\title{
Andrew GAMBLE, Between Europe and America: The Future of British Politics
}

Basingstoke : Palgrave Macmillan, 2003

\section{Agnès Alexandre-Collier}

\section{OpenEdition \\ Journals}

Édition électronique

URL : http://journals.openedition.org/rfcb/3475

DOI : $10.4000 /$ rfcb.3475

ISSN : 2429-4373

Éditeur

CRECIB - Centre de recherche et d'études en civilisation britannique

Édition imprimée

Date de publication : 1 avril 2005

ISBN : 2-911580-20-6

ISSN : 0248-9015

Référence électronique

Agnès Alexandre-Collier, " Andrew GAMBLE, Between Europe and America : The Future of British Politics », Revue Française de Civilisation Britannique [En ligne], XIII-2 | 2005, mis en ligne le 01 avril 2005, consulté le 25 septembre 2020. URL : http://journals.openedition.org/rfcb/3475 ; DOI : https://doi.org/ $10.4000 /$ rfcb.3475

Ce document a été généré automatiquement le 25 septembre 2020.

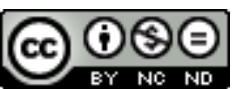

Revue française de civilisation britannique est mis à disposition selon les termes de la licence Creative Commons Attribution - Pas d'Utilisation Commerciale - Pas de Modification 4.0 International. 


\title{
Andrew GAMBLE, Between Europe and America: The Future of British Politics
}

\author{
Basingstoke : Palgrave Macmillan, 2003
}

Agnès Alexandre-Collier

\section{RÉFÉRENCE}

Andrew GAMBLE, Between Europe and America : The Future of British Politics, Basingstoke : Palgrave Macmillan, 2003, 262 p., ISBN 0-333-55571-6.

1 Cet ouvrage s'inscrit dans la continuité des travaux de l'auteur sur le déclin économique et social du Royaume-Uni depuis la Seconde Guerre mondiale ${ }^{1}$. L'auteur de Britain in Decline (Londres: Macmillan, 1981 \& 1994) remonte ici aux origines du processus au moment où le Royaume-Uni était à l'apogée de sa puissance sur la scène internationale. Il s'interroge cette fois-ci sur les causes qui ont favorisé l'émergence de l'exceptionnalisme du pays en particulier dans sa relation avec l'Empire, l'Europe, les États-Unis et le monde anglophone. L'auteur ajoute à cette liste un quatrième " cercle », celui de l'Union, c'est-à-dire des liens qui unissent l'Angleterre avec les nations périphériques du Royaume-Uni car d'emblée, Andrew Gamble insiste sur le caractère essentiellement anglais de cet exceptionnalisme.

2 En effet, l'auteur met en évidence les différents facteurs historiques qui ont permis la mise en œuvre d'un "modèle anglais" révéré par le reste du monde comme un exemple d'organisation politique, économique et sociale dont les autres pays se sont efforcés de copier les principaux aspects : le capitalisme libéral, ce que l'auteur appelle 'self-government' au XIX ${ }^{\mathrm{e}}$ siècle et le socialisme démocratique au XX ${ }^{\mathrm{e}}$ siècle. L'Angleterre est présentée comme le principal pionnier du capitalisme, le premier pays à s'industrialiser et à asseoir sa domination technologique, commerciale et financière. L'auteur précise que si le capitalisme doit être perçu comme un projet britannique et non spécifiquement anglais, il est néanmoins devenu une caractéristique fondamentale de l'identité anglaise. Quant au second aspect du modèle - 'self-government' - 
l'Angleterre a aussi fait figure de pionnier en instaurant dès 1688 , après une brève expérience "républicaine ", le premier 'representative and parliamentary government, but within a constitution which retained the monarchical principle of undivided and unlimited sovereignty' (p. 13). Quant au socialisme démocratique, Andrew Gamble montre comment l'Angleterre, disposant après la révolution industrielle d'un prolétariat massif, a été le premier pays à proposer des formes d'organisation sociale et des programmes socialistes œuvrant pour le bien-être de la classe ouvrière.

Ce faisant, l'auteur insiste sur l'impact du modèle anglais dans la structure sociale, économique et politique du Royaume-Uni et montre surtout quelles ont pu être les conséquences de sa désintégration sur l'identité même du pays. Dès lors, la question du choix entre l'Amérique et l'Europe, qui réside au cœur de l'ouvrage, est loin de se résumer à des motivations purement géopolitiques et militaires. Ces deux aires géographiques représentent surtout deux modèles différents d'organisation politique, économique et sociale qui occupent une place prépondérante dans l'imagination britannique et entre lesquels le Royaume-Uni ne peut se résoudre à faire un choix. Car, explique Andrew Gamble, 'with Empire gone, the future of Britain as an independent nation now depends on the multilateral relationships it forges with the rest of the world, and to which of those it chooses to give priority. Europe and America in this sense offer different futures. The choice is not an exclusive one, because Europe and America are not monolithic, but highly complex and differentiated political spaces' (p. 220). En ce sens, ces deux perspectives - ces deux «espaces politiques" selon l'expression de l'auteur - sont apparues pour le Royaume-Uni comme les deux seules solutions possibles face au vide laissé par la disparition du modèle anglais. L'auteur, également spécialiste du Parti conservateur et de ses dissensions sur la question de l'intégration européenne, propose une explication à la fois pertinente et exhaustive des tensions actuelles au sein des partis britanniques. À l'instar de l'Europe qui demeure l'enjeu par excellence qui divise les conservateurs, l'Amérique, observe-t-il, apparaît aujourd'hui comme la principale "ligne de faille » des travaillistes, comme l'a illustré la crise irakienne. Mais ce qui constitue une piste de réflexion particulièrement novatrice, c'est la façon dont Andrew Gamble identifie ces tensions comme la conséquence d'un long processus dont il retrace méthodiquement la trajectoire. Selon l'auteur, c'est précisément parce que les Partis travailliste et conservateur ont parfaitement intégré l'existence du modèle anglais dans leurs politiques et leur pratiques gouvernementales qu'ils ont dû faire face à une véritable crise lorsque celui-ci a volé en éclats dans les années 1970 et 1980.

Le thatchérisme et le blairisme ont donc constitué des étapes fondamentales dans l'histoire de ces partis car pour la première fois, ils leur ont permis de dépasser la problématique du déclin et d'apporter des solutions concrètes pour affronter cette crise. À l'origine d'une transformation radicale de l'identité même du Royaume-Uni, en particulier de l'État, des institutions et des partis politiques britanniques, ces périodes préfigurent une nouvelle ère pour le pays, celle d'un avenir européen inéluctable. L'heure n'est plus, explique l'auteur, au dilemme qui tiraille le Royaume-Uni entre sa relation passionnelle et ancestrale avec les États-Unis et le mariage de raison qui l'unit depuis plus de trente ans à l'Union européenne. Il s'agit pour ce pays de redéfinir les principes de son adhésion à une Europe dont les contours et le projet doivent être mieux définis ou bien d'accepter un nouvel isolement qui risquerait toutefois, cette fois-ci, de lui être fatal. 


\section{NOTES}

1. Cette théorie du déclin connaît un grand nombre d'adeptes au Royaume-Uni puisqu'il existe tout un champ de la recherche en sciences sociales consacré à cette question, comprenant des ouvrages aussi variés que celui d'Andrew Gamble mais aussi The Economic Decline of Modern Britain: The Debate between Left and Right de David Coates et John Hillard (Brighton: Wheatsheaf, 1986), Britain's Decline: Problems and Perspectives de Alan Sked (Oxford: Blackwell, 1987), ou encore Rethinking British Decline sous la direction de Richard English et Michael Kenny (London: Macmillan, 1999).

\section{AUTEURS}

\section{AGNÈS ALEXANDRE-COLLIER}

Université de Franche-Comté 